\title{
$\beta$-Lactam Resistance in Upper Respiratory Tract Pathogens Isolated from a Tertiary Hospital in Malaysia
}

\author{
Soo Tein Ngoi ${ }^{1,+}{ }^{\mathbb{D}}$, Anis Najwa Muhamad ${ }^{1,+}$, Cindy Shuan Ju Teh ${ }^{1, *}$, Chun Wie Chong ${ }^{2} \mathbb{D}$, \\ Kartini Abdul Jabar ${ }^{1}\left(\mathbb{D}\right.$, Lay Ching Chai ${ }^{3}\left(\mathbb{D}\right.$, Kin Chong Leong ${ }^{4}$, Loong Hua Tee ${ }^{4}$ and Sazaly AbuBakar ${ }^{1,5}$ \\ 1 Department of Medical Microbiology, Faculty of Medicine, Universiti Malaya, \\ Kuala Lumpur 50603, Malaysia; ngoisootein@um.edu.my (S.T.N.); anisnajwa@um.edu.my (A.N.M.); \\ kartini.abduljabar@ummc.edu.my (K.A.J.); sazaly@um.edu.my (S.A.) \\ 2 School of Pharmacy, Monash University Malaysia, Bandar Sunway 47500, Malaysia; \\ chong.chunwie@monash.edu \\ 3 Faculty of Science, Institute of Biological Sciences, Universiti Malaya, Kuala Lumpur 50603, Malaysia; \\ lcchai@um.edu.my \\ 4 Shionogi Singapore Pte Ltd., Anson Road, \#34-14 International Plaza, Singapore 079903, Singapore; \\ kinchong.leong@shionogi.com.sg (K.C.L.); loonghua.tee@shionogi.com.sg (L.H.T.) \\ 5 Tropical Infectious Diseases Research and Education Centre (TIDREC), Universiti Malaya, \\ Kuala Lumpur 50603, Malaysia \\ * Correspondence: cindysjteh@um.edu.my; Tel.: +603-79676674 \\ + Co-first authors.
}

check for updates

Citation: Ngoi, S.T.; Muhamad, A.N.; Teh, C.S.J.; Chong, C.W.; Abdul Jabar, K.; Chai, L.C.; Leong, K.C.; Tee, L.H.; AbuBakar, S. $\beta$-Lactam Resistance in Upper Respiratory Tract Pathogens Isolated from a Tertiary Hospital in Malaysia. Pathogens 2021, 10, 1602. https://doi.org/10.3390/ pathogens10121602

Academic Editor: Stephen Tristram

Received: 25 October 2021

Accepted: 2 December 2021

Published: 9 December 2021

Publisher's Note: MDPI stays neutral with regard to jurisdictional claims in published maps and institutional affiliations.

Copyright: (c) 2021 by the authors. Licensee MDPI, Basel, Switzerland. This article is an open access article distributed under the terms and conditions of the Creative Commons Attribution (CC BY) license (https:// creativecommons.org/licenses/by/ $4.0 /)$.

\begin{abstract}
The rise of antimicrobial resistance (AMR) among clinically important bacteria, including respiratory pathogens, is a growing concern for public health worldwide. Common causative bacteria for upper respiratory tract infections (URTIs) include Streptococcus pneumoniae and Haemophilus influenzae, and sometimes Staphylococcus aureus. We assessed the $\beta$-lactam resistant trends and mechanisms of 150 URTI strains isolated in a tertiary care hospital in Kuala Lumpur Malaysia. High rates of non-susceptibility to penicillin G (38\%), amoxicillin-clavulanate (48\%), imipenem (60\%), and meropenem (56\%) were observed in S. pneumoniae. Frequent mutations at STMK and SRNVP motifs in PBP1a (41\%), SSNT motif in PBP2b (32\%), and STMK and LKSG motifs in PBP2x (41\%) were observed in S. pneumoniae. H. influenzae remained highly susceptible to most $\beta$-lactams, except for ampicillin. Approximately half of the ampicillin non-susceptible $H$. influenzae harboured PBP3 mutations (56\%) and only blaTEM was detected in the ampicillin-resistant strains (47\%). Methicillin-susceptible S. aureus (MSSA) strains were mostly resistant to penicillin G (92\%), with at least two-fold higher median minimum inhibitory concentrations (MIC) for all penicillin antibiotics (except ticarcillin) compared to S. pneumoniae and H. influenzae. Almost all URTI strains (88-100\%) were susceptible to cefcapene and flomoxef. Overall, $\beta$-lactam antibiotics except penicillins remained largely effective against URTI pathogens in this region.
\end{abstract}

Keywords: antimicrobial resistance; $\beta$-lactamase; Haemophilus influenzae; penicillin resistance; penicillin-binding proteins; Staphylococcus aureus; Streptococcus pneumoniae

\section{Introduction}

Respiratory tract infections (RTIs) are generally classified into either upper or lower respiratory tract infections [1]. Based on national surveillance conducted by the Ministry of Health (MOH) Malaysia, RTIs accounted for approximately $68 \%$ of the patients admitted to government hospitals due to diseases of the respiratory system [2]. Among the RTIs, pneumonia is of particularly high risk to susceptible hosts in healthcare settings [3] and is the world's leading infectious cause of death for infants under five, accounting for $16 \%$ of child deaths [4]. In Malaysia, pneumonia is one of the most common nosocomial infections, second only to clinical sepsis cases [5]. Common bacterial pathogens causing pneumonia are Streptococcus pneumoniae, Haemophilus influenzae, and sometimes Staphylococcus aureus 
(4). Non-viral pneumonia is and has been the main cause of death (99\%) among patients' death due to RTIs in Malaysian hospitals [6].

Antibiotic treatment is often contraindicated for healthy individuals with uncomplicated acute RTIs. However, in RTIs caused by bacteria, amoxicillin or penicillin antibiotics are often the drugs of choice, followed by macrolides or fluoroquinolones in cases of penicillin allergy $[4,7,8]$. In Malaysia, higher rates of antibiotic prescription for upper respiratory tract infections (URTIs) were observed in private clinics $(46.7 \%)$ compared to public clinics (27.8\%) [9]. Most of the antibiotics prescribed were penicillin and macrolides, with broad-spectrum antibiotics being the preferred option [9]. The higher-than-usual antibiotic prescription rates for URTIs, which are mainly caused by viruses, may increase the risk of bacterial pathogens developing antimicrobial resistance (AMR) [9]. The first-line drugs that are commonly used for the treatment of acute RTIs mainly comprise $\beta$-lactam antibiotics $[4,7,8]$. However, $\beta$-lactam resistance among the clinically important bacteria, including those that cause RTIs, has been on a global rise [10]. Therefore, continuous efforts to monitor the AMR trends and to explore new antibacterial agents are essential to reduce the impact of AMR on public health [11]. This study aimed to investigate the $\beta$-lactam resistance trends and mechanisms among S. pneumoniae, H. influenzae, and S. aureus strains isolated from URTI patients.

\section{Results}

The patient's demographic data and S. pneumoniae serotypes are summarized in Table 1. Table 2 summarizes the minimum inhibitory concentration (MIC) data for all 150 bacterial strains.

Table 1. Summary of demographic data, source of specimen and serotype of the URTI strains $(n=150)$.

\begin{tabular}{cccc}
\hline & $\begin{array}{c}\text { S. pneumoniae } \\
(\boldsymbol{n}) \mathbf{( \% )}\end{array}$ & $\begin{array}{c}\text { H. influenzae } \\
(\boldsymbol{n}) \mathbf{( \% )}\end{array}$ & $\begin{array}{c}\text { MSSA } \\
(\boldsymbol{n}) \mathbf{( \% )}\end{array}$ \\
\hline Gender & & & \\
Female & $27(54)$ & $21(42)$ & $18(36)$ \\
Male & $23(46)$ & $29(58)$ & $32(64)$ \\
\hline Age Range & & & \\
$<1$ year & $7(14)$ & $5(10)$ & $12(24)$ \\
$1-17$ & $43(86)$ & $45(90)$ & $10(20)$ \\
$18-59$ & $0(0)$ & $0(0)$ & $18(36)$ \\
$\geq 60$ & $0(0)$ & $0(0)$ & $10(20)$ \\
\hline Source of Specimen & & & \\
Bronchoalveolar lavage & $2(4)$ & $0(0)$ & $0(0)$ \\
Nasopharyngeal swab & $46(92)$ & $50(100)$ & $50(100)$ \\
Sputum & $2(4)$ & $0(0)$ & $0(0)$ \\
\hline Serotype $\mathbf{1}$ & & & - \\
3 & $1(2)$ & - & - \\
34 & $1(2)$ & - & - \\
11A/D/F & $3(6)$ & - & - \\
15A/F & $1(2)$ & - & - \\
19A & $2(4)$ & - & - \\
19F & $11(22)$ & - & - \\
$23 \mathrm{~A}$ & $3(6)$ & - & - \\
23F & $2(4)$ & - & - \\
6A/6B & $11(22)$ & - & - \\
6C & $3(6)$ & - & \\
Non-typeable & $12(24)$ & & - \\
\hline
\end{tabular}

${ }^{1}$ Polymerase chain reaction (PCR) serotyping was only performed on S. pneumoniae strains $(n=50)$. 
Table 2. Summary of MIC data for S. pneumoniae $(n=50)$, H. influenzae $(n=50)$, and methicillin-susceptible $S$. aureus (MSSA) $(n=50)$.

\begin{tabular}{|c|c|c|c|c|c|c|c|c|c|}
\hline \multirow{2}{*}{ Antimicrobial Agent } & \multicolumn{3}{|c|}{ S. pneumoniae ${ }^{1}$} & \multicolumn{3}{|c|}{ H. influenzae ${ }^{1}$} & \multicolumn{3}{|c|}{ MSSA $^{1}$} \\
\hline & MIC Range & $\mathrm{MIC}_{50}$ & $\mathrm{MIC}_{90}$ & MIC Range & $\mathrm{MIC}_{50}$ & $\mathrm{MIC}_{90}$ & MIC Range & $\mathrm{MIC}_{50}$ & $\mathrm{MIC}_{90}$ \\
\hline Ampicillin & $\leq 0.125-128$ & 16 & 64 & $0.5->256$ & 4 & $>256$ & $\leq 0.125-128$ & 32 & 64 \\
\hline Penicillin G & $\leq 0.03-8$ & 2 & 4 & $0.25->64$ & 1 & $>64$ & $\leq 0.03->64$ & 32 & $>64$ \\
\hline Piperacillin & $\leq 0.03-16$ & 2 & 8 & $\leq 0.03->64$ & $\leq 0.03$ & $>64$ & $0.5->128$ & 64 & $>128$ \\
\hline Ticarcillin & $1->64$ & $\geq 64$ & $>64$ & $0.25->64$ & 2 & $>64$ & $2-32$ & 16 & 32 \\
\hline Amoxicillin-clavulanate (2:1) & $\leq 0.03 / 0.015-32 / 16$ & $\overline{2} / 1$ & $8 / 4$ & $0.125 / 0.06->64 / 32$ & $2 / 1$ & $32 / 16$ & $\leq 0.125 / 0.06-8 / 4$ & $2 / 1$ & $4 / 2$ \\
\hline Cefotaxime-clavulanate $^{2}$ & $\leq 0.03-1$ & 0.06 & 0.5 & $\leq 0.03-0.5$ & $\leq 0.03$ & 0.25 & $0.25-2$ & 1 & 2 \\
\hline Ceftazidime-clavulanate ${ }^{2}$ & $\leq 0.03-32$ & 0.125 & 2 & $\leq 0.03-4$ & 0.25 & 2 & $16-256$ & 64 & 128 \\
\hline Piperacillin-tazobactam ${ }^{3}$ & $\leq 0.03-2$ & 0.5 & 1 & $\leq 0.03-1$ & $\leq 0.03$ & 1 & $0.5-64$ & 16 & 64 \\
\hline Ticarcillin-clavulanate ${ }^{4}$ & $1->64$ & $\geq 64$ & $>64$ & $0.125-16$ & 1 & 2 & $0.5-16$ & 8 & 8 \\
\hline Cefmetazole & $0.125-64$ & 4 & 32 & $1-8$ & 8 & 8 & $0.5-2$ & 1 & 2 \\
\hline Cefoxitin & $32->64$ & $>64$ & $>64$ & $1->64$ & 4 & $>64$ & $2-4$ & 4 & 4 \\
\hline Cefcapene & $\leq 0.03-8$ & 0.5 & 2 & $\leq 0.03-1$ & $\leq 0.03$ & 0.125 & $0.125-1$ & 0.5 & 1 \\
\hline Cefoperazone & $\leq 0.03-32$ & 4 & 32 & $\leq 0.03-16$ & $\overline{0} .125$ & 8 & $0.25-8$ & 4 & 8 \\
\hline Cefotaxime & $\leq 0.03-2$ & 0.125 & 2 & $\leq 0.03-4$ & $\leq 0.03$ & 0.25 & $0.25-2$ & 1 & 2 \\
\hline Ceftazidime & $\leq 0.03-64$ & 2 & 16 & $0.06-64$ & 1 & 8 & $32->256$ & 128 & 256 \\
\hline Ceftriaxone & $\leq 0.03-4$ & 0.5 & 2 & $\leq 0.03-0.5$ & $\leq 0.03$ & 0.25 & $2-4$ & 2 & 4 \\
\hline Meropenem & $\leq 0.03-2$ & 0.5 & 1 & $\leq 0.03-0.5$ & 0.125 & 0.5 & $\leq 0.03-0.06$ & 0.06 & 0.06 \\
\hline Flomoxef & $0.125-16$ & 0.5 & 16 & $0.5-4$ & 1 & 4 & $0.06-0.5$ & 0.25 & 0.25 \\
\hline Oxacillin 5 & - & - & - & - & - & - & $\leq 0.125-0.5$ & 0.25 & 0.5 \\
\hline
\end{tabular}

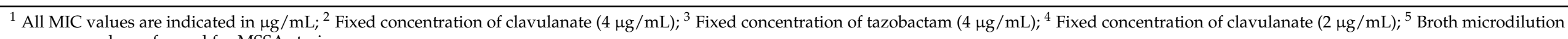
assay was only performed for MSSA strain. 


\subsection{Streptococcus Pneumoniae}

S. pneumoniae showed the highest rates of resistance to imipenem (44\%) and meropenem (38\%) (Figure 1). Among the two major S. pneumoniae serotypes observed in this study, serotype $19 \mathrm{~F}$ showed higher rates of non-susceptibility to penicillin $(55 \%)$, imipenem $(91 \%)$, and meropenem (91\%) compared to serotype 6A/6B (36\%, 55\%, 45\%, respectively). The potential non -susceptibility to ampicillin was predicted in $74 \%$ of the $S$. pneumoniae strains (penicillin MIC $>0.06 \mu \mathrm{g} / \mathrm{mL}$ ) [8]. Simultaneous resistance to two-or-more $\beta$-lactam antibiotics was observed in $34 \%$ of the strains (Supplementary Table S1).

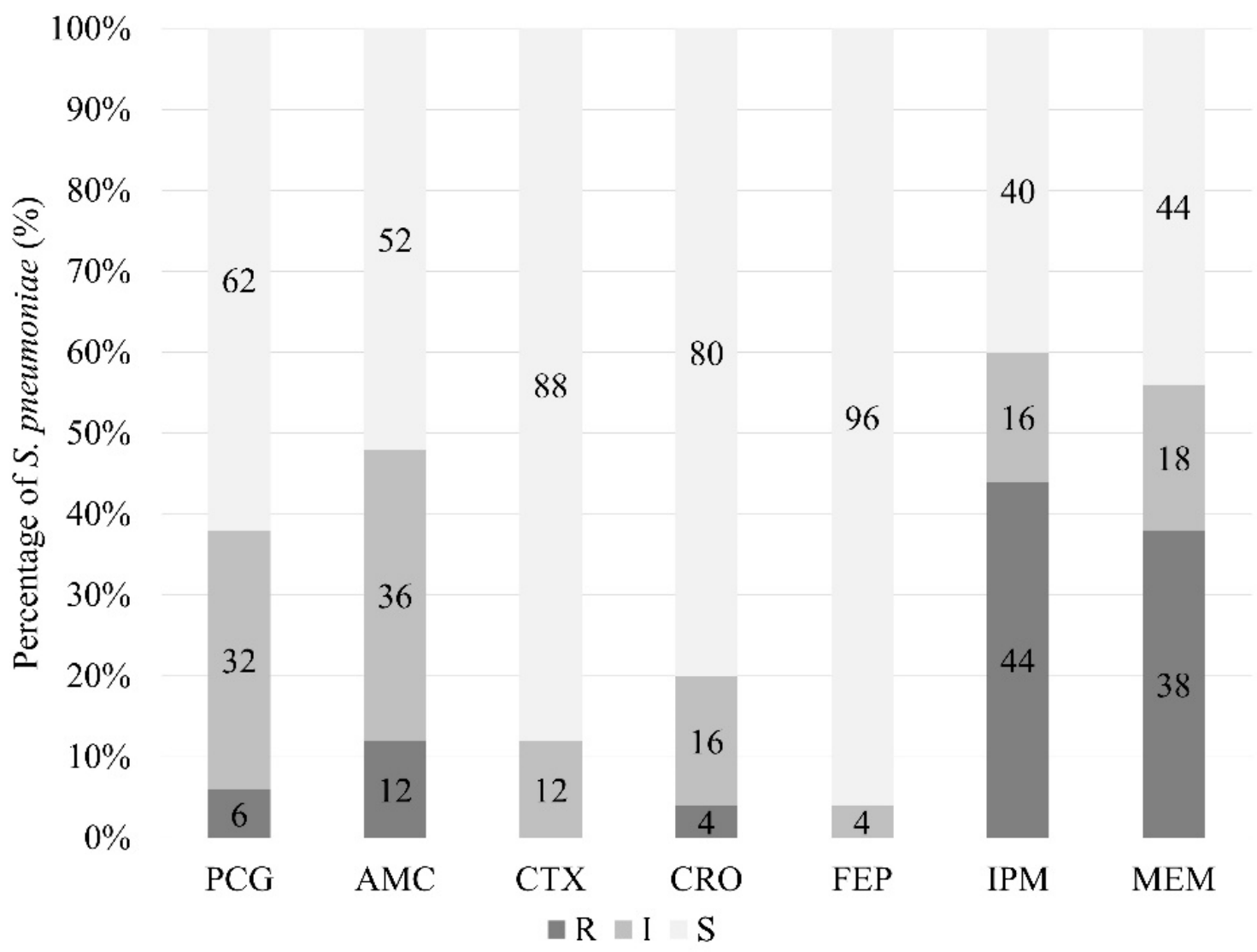

Figure 1. Proportions of $S$. pneumoniae strains $(n=50)$ with different susceptibility phenotypes. The MIC values for penicillin G (PCG), amoxicillin-clavulanate (AMC), cefotaxime (CTX), ceftriaxone (CRO), cefepime (FEP), imipenem (IPM), and meropenem (MEM) were interpreted based on the Clinical and Laboratory Standards Institute (CLSI) non-meningitis breakpoints.

High-level resistance ( $\mathrm{MIC}_{50} \geq 64 \mu \mathrm{g} / \mathrm{mL}$ ) to ticarcillin, ticarcillin-clavulanate, and cefoxitin was observed among the S. pneumoniae strains (Table 2). Penicillin antibiotics showed relatively higher $\mathrm{MIC}_{50}$ values $(2-\geq 64 \mu \mathrm{g} / \mathrm{mL})$, compared to other groups of $\beta$-lactam. Generally, $\beta$-lactam combination agents remained highly active against S. pneumoniae $\left(\mathrm{MIC}_{50} \leq 0.5 \mu \mathrm{g} / \mathrm{mL}\right.$ ), except amoxicillin-clavulanate and ticarcillinclavulanate. Similarly, most third and fourth-generation cephalosporins (cefcapene, cefotaxime, ceftriaxone, and cefepime) and the oxacephem antibiotic flomoxef recorded low $\mathrm{MIC}_{50}$ values $(\leq 0.5 \mu \mathrm{g} / \mathrm{mL})$. Cefotaxime-clavulanate showed highest activity against the S. pneumoniae $\left(\mathrm{MIC}_{90}=0.5 \mu \mathrm{g} / \mathrm{mL}\right)$.

Thirty-seven ampicillin non-susceptible S. pneumoniae strains were examined for amino acid substitutions in three conserved motifs of the $p b p$ genes (Table 3). Seven strains failed to produce amplicons for all three $p b p$ genes, probably due to primer-binding sites alteration. The KTG motif in the penicillin-binding protein PBP1a and SVVK in PBP2b remained highly conserved. All but five mutation profiles (M01, M07, M09, M11, and M14) conferred reduced susceptibility to penicillin G (MIC $\geq 4 \mu \mathrm{g} / \mathrm{mL}$ ). M12 and M13 
profiles were penicillin-resistant S. pneumoniae (PRSP). Mutations beyond the conserved motifs were identified in PBP1a (block substitution of Thr-Ser-Gln-Phe ( $\left.\mathrm{T}^{574} \mathrm{SQF}\right)$ by AsnThr-Gly-Tyr (N ${ }^{574}$ TGY); $n=16$ ) and PBP2b (Ser-411-Pro, Asn-421-Tyr, Thr-425-Lys, and Gln-426-Ala/Leu; $n=11)$.

\subsection{Haemophilus Influenzae}

The majority of the $H$. influenzae strains were resistant to ampicillin (72\%) and nonsusceptible to ceftazidime (20\%), amoxicillin-clavulanate $(18 \%)$, cefotaxime $(6 \%)$, and imipenem $(6 \%)$. All strains remained susceptible to piperacillin-tazobactam, ceftriaxone, cefepime, and meropenem. Simultaneous resistance/non-susceptibility to two to three $\beta$-lactam antibiotics was observed in approximately one-third of the strains $(n=16)$ (Supplementary Table S2).

High-level resistance was not common among the $H$. influenzae strains (Table 2). The $\mathrm{MIC}_{50}$ values of amoxicillin-clavulanate, piperacillin-tazobactam, cefotaxime, ceftazidime, ceftriaxone, cefepime, imipenem, and meropenem were within the susceptible range (Clinical and Laboratory Standards Institute, CLSI interpretive criteria). Cefmetazole $\left(\mathrm{MIC}_{50}=8 \mu \mathrm{g} / \mathrm{mL}\right)$, ampicillin $\left(\mathrm{MIC}_{50}=4 \mu \mathrm{g} / \mathrm{mL}\right)$, and cefoxitin $\left(\mathrm{MIC}_{50}=4 \mu \mathrm{g} / \mathrm{mL}\right)$ were relatively less active against the $H$. influenzae strains. The majority of the $\beta$-lactam combination agents, third and fourth generation cephalosporins, piperacillin, and meropenem remained highly active against $H$. influenzae $\left(\mathrm{MIC}_{50} \leq 0.25 \mu \mathrm{g} / \mathrm{mL}\right)$. H. influenzae were mostly inhibited by low concentrations of cefotaxime-clavulanate, cefcapene, cefotaxime, ceftriaxone, cefepime, and meropenem ( $\left.\mathrm{MIC}_{90} \leq 0.5 \mu \mathrm{g} / \mathrm{mL}\right)$. Contrarily, high concentrations of penicillin were required to inhibit the growth of most of the $H$. influenzae strains $\left(\mathrm{MIC}_{90}>64 \mu \mathrm{g} / \mathrm{mL}\right)$.

Thirty-nine ampicillin non-susceptible $H$. influenzae strains were examined for $\beta$-lactamase $(b l a)$ genes and ftsI mutations (Table 4 ). The bla $a_{\text {TEM }}$ gene was detected in $44 \%(n=17)$ of the strains, while $b l a_{\mathrm{ROB}}$ was totally absent. The bla $a_{\mathrm{TEM}}$-positive strains were further classified as $\beta$-lactamase positive ampicillin-resistant (BLPAR; harbours wild type $f t s I$ gene) $(n=7)$ or $\beta$-lactamase positive amoxicillin-clavulanate resistant (BLPACR; harbours ftsI gene mutation) $(n=10)$. Approximately one-third (31\%) of the ampicillinresistant strains lacked $\beta$-lactamase but harboured a mutated ftsI gene ( $\beta$-lactamase negative ampicillin-resistant, BLNAR). The amino acid substitutions in the ftsI gene were generally more diverse in BLNAR strains than in BLPACR strains.

\subsection{Methicillin-Susceptible Staphylococcus aureus}

Susceptibility to oxacillin (MIC $\leq 2 \mu \mathrm{g} / \mathrm{mL}$ ) and cefoxitin (MIC $\leq 4 \mu \mathrm{g} / \mathrm{mL}$ ) confirmed the methicillin-susceptible phenotype of the $S$. aureus strains (Table 2). The majority of the methicillin-susceptible $S$. aureus (MSSA) strains showed a penicillin-resistant phenotype (92\%). Higher MIC values of penicillinase-labile agents such as ampicillin, piperacillin, and ticarcillin $\left(16 \leq \mathrm{MIC}_{50} \leq 64 \mu \mathrm{g} / \mathrm{mL}\right)$ were observed among penicillin-resistant MSSA. High MIC values were recorded for ceftazidime $\left(\mathrm{MIC}_{50}=128 \mu \mathrm{g} / \mathrm{mL}\right)$ and ceftazidimeclavulanate $\left(\mathrm{MIC}_{50}=64 \mu \mathrm{g} / \mathrm{mL}\right)$. Carbapenems $\left(\mathrm{MIC}_{50} \leq 0.06 \mu \mathrm{g} / \mathrm{mL}\right)$ generally had lower $\mathrm{MIC}_{50}$ values than $\beta$-lactam combination agents $\left(1 \leq \mathrm{MIC}_{50} \leq 64 \mu \mathrm{g} / \mathrm{mL}\right)$ and cephems $\left(1 \leq \mathrm{MIC}_{50} \leq 128 \mu \mathrm{g} / \mathrm{mL}\right)$, except cefcapene. Most MSSA strains remained highly susceptible to carbapenems, cefcapene and flomoxef $\left(\mathrm{MIC}_{90} \leq 1 \mu \mathrm{g} / \mathrm{mL}\right)$. 
Table 3. Mutations identified in the penicillin-binding proteins (PBPs) in S. pneumoniae.

\begin{tabular}{|c|c|c|c|c|c|c|c|c|c|c|c|c|}
\hline \multirow{3}{*}{$\begin{array}{c}\text { Mutation } \\
\text { Profile }^{1}\end{array}$} & \multirow{3}{*}{$\begin{array}{l}\text { No. of } \\
\text { Strains }\end{array}$} & \multirow{3}{*}{$\begin{array}{c}\text { Ampicillin } \\
\text { MIC Range } \\
(\mu \mathrm{g} / \mathrm{mL})\end{array}$} & \multirow{3}{*}{$\begin{array}{l}\text { Penicillin } \\
\text { G MIC } \\
\text { Range } \\
(\mu \mathrm{g} / \mathrm{mL})\end{array}$} & \multicolumn{9}{|c|}{ Penicillin-Binding Protein (PBP) motifs ${ }^{2,3}$} \\
\hline & & & & \multicolumn{3}{|c|}{ PBP1a } & \multicolumn{3}{|c|}{ PBP2b } & \multicolumn{3}{|c|}{ PBP2x } \\
\hline & & & & $\begin{array}{c}\text { STMK } \\
(370-373)\end{array}$ & $\begin{array}{c}\text { SRNVP } \\
(428-432)\end{array}$ & $\begin{array}{c}\text { KTG } \\
(557-559)\end{array}$ & $\begin{array}{c}\text { SVVK } \\
(385-388)\end{array}$ & $\begin{array}{c}\text { SSNT } \\
(442-445)\end{array}$ & $\begin{array}{c}\text { KTGTA } \\
(614-618)\end{array}$ & $\begin{array}{c}\text { STMK } \\
(337-340)\end{array}$ & $\begin{array}{c}\text { HSSN } \\
(395-397)\end{array}$ & $\begin{array}{c}\text { LKSG } \\
(546-549)\end{array}$ \\
\hline M01 & 1 & 4 & 1 & - & - & - & - & - & - & - & $\mathrm{L}-$ & $\mathrm{V}-$ \\
\hline M02 & 3 & $16-64$ & 4 & $-S-$ & - $\mathrm{T}$ & - & - & - & - & $-\mathrm{A}-$ & - & $\mathrm{V}-$ \\
\hline M03 & 3 & $<0.125-64$ & $1-4$ & $-S-$ & - $\mathrm{T}$ & - & - & - & - & - & 一 & - \\
\hline M04 & 1 & 16 & 4 & - & - & - & - & $-\mathrm{A}$ & $-\mathrm{G}$ & $-\mathrm{A}-$ & 一 & $\mathrm{V}-$ \\
\hline M06 & 3 & $4-32$ & $2-4$ & -S- & - $\mathrm{T}$ & - & 一 & $-\mathrm{A}$ & - & $-\mathrm{A}-$ & - & $\mathrm{V}-$ \\
\hline M07 & 1 & 2 & 0.25 & - & - & - & 一 & $-\mathrm{A}$ & - & - & 一 & - \\
\hline M08 & 2 & $4-16$ & $0.25-4$ & 一 & - & - & 一 & $-\mathrm{A}$ & - & $-\mathrm{A}-$ & 一 & $\mathrm{V}-$ \\
\hline M09 & 2 & $2-32$ & $0.5-2$ & - & - & - & - & - & - & $-A-$ & - & $\mathrm{V}-$ \\
\hline M10 & 1 & 16 & 4 & $-\mathrm{A}-$ & - $\mathrm{T}$ & - & - & - & - & - & - & - \\
\hline M11 & 1 & 16 & 2 & $-\mathrm{A}-$ & - $\mathrm{T}$ & - & - & $-\mathrm{A}$ & - & $-\mathrm{A}-$ & - & $\mathrm{V}-$ \\
\hline M12 & 1 & 64 & 8 & $-S-$ & - $\mathrm{T}$ & - & - & $-\mathrm{A}$ & $-\mathrm{G}$ & $-A-$ & - & $\mathrm{V}-$ \\
\hline M13 & 1 & 128 & 8 & - & - & - & - & - & - & $-A-$ & - & - \\
\hline M14 & 1 & 32 & 2 & 一 & - & - & - & - & - & -AF- & - & $\mathrm{V}-$ \\
\hline
\end{tabular}

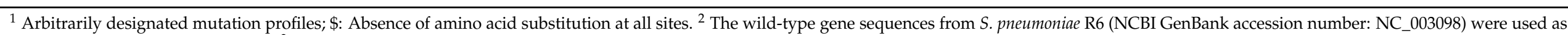

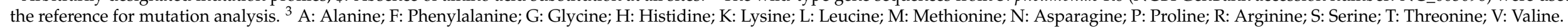


Table 4. Summary of ftsI mutation sites and classification of ampicillin-resistant H. influenzae.

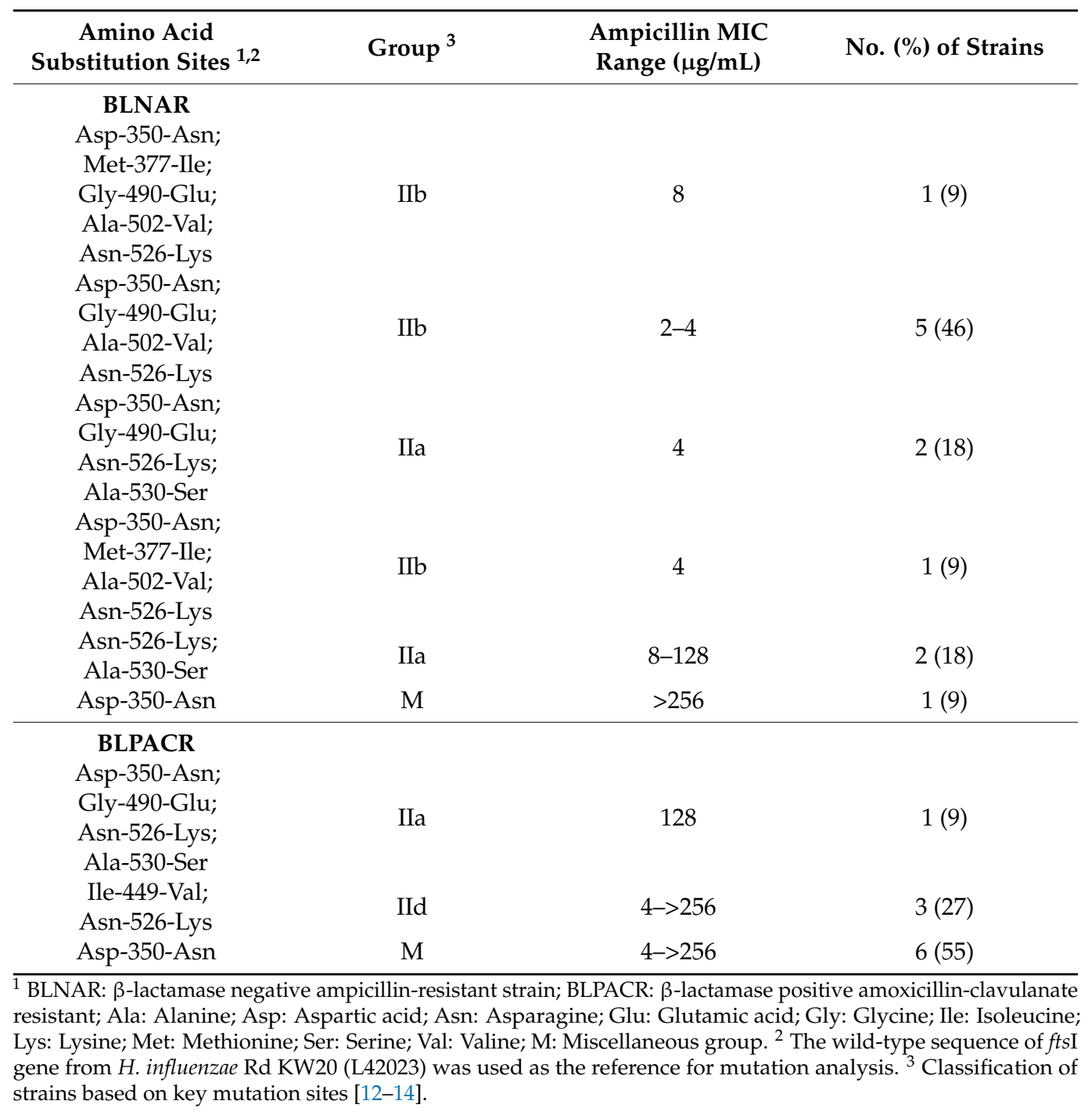

\subsection{In Vitro Efficiency of Flomoxef and Cefcapene}

The susceptibility of $H$. influenzae to penicillin G was negatively correlated with both flomoxef and cefcapene, while that of amoxicillin-clavulanate was only negatively correlated with cefcapene (Figure 2). In MSSA, susceptibility to penicillin G was positively correlated with flomoxef (Figure 3a) but negatively correlated with cefcapene (Figure 3b). Similarly, a positive relationship was only observed between piperacillin-tazobactam and flomoxef in MSSA (Figure 3). For S. pneumoniae strains, none of the $\beta$-lactam antibiotics selected for comparison showed an obvious correlation with both flomoxef and cefcapene (data not shown). An overall comparison including all URTI strains revealed negative correlations between penicillin $G$ and piperacillin-tazobactam with flomoxef, but the opposite with cefcapene (Figure 4). 


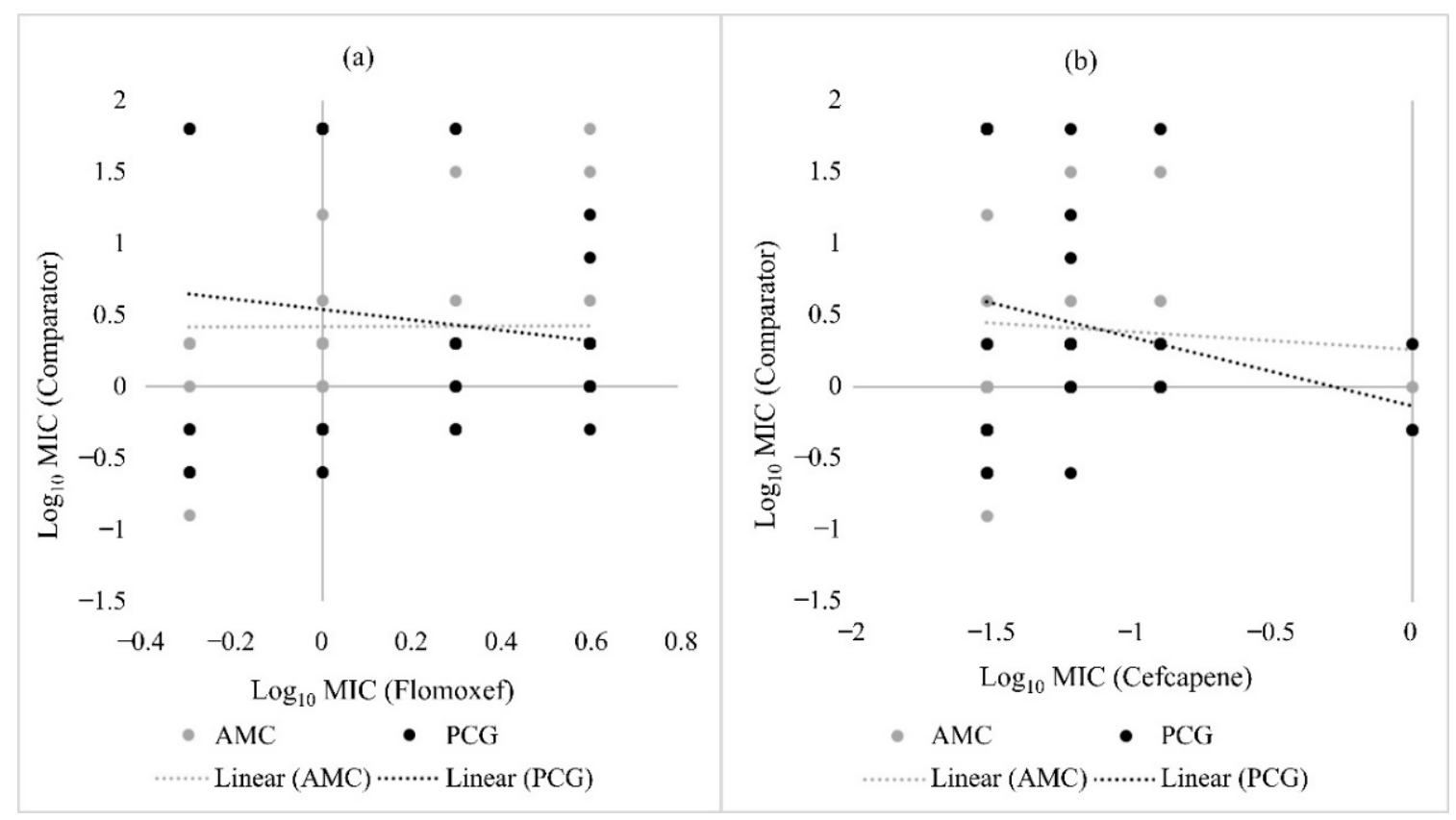

Figure 2. Scatter plots comparing the in vitro activity of amoxicillin-clavulanate, penicillin $\mathrm{G}$, flomoxef and cefcapene against $H$. influenzae. (a) compares the $\log _{10}$ MIC values of amoxicillin-clavulanate (AMC) and penicillin G (PCG) against that of flomoxef, while (b) compares the $\log _{10}$ MIC values of AMC and PCG against that of cefcapene. The dotted lines indicate the linear correlation between the comparators.

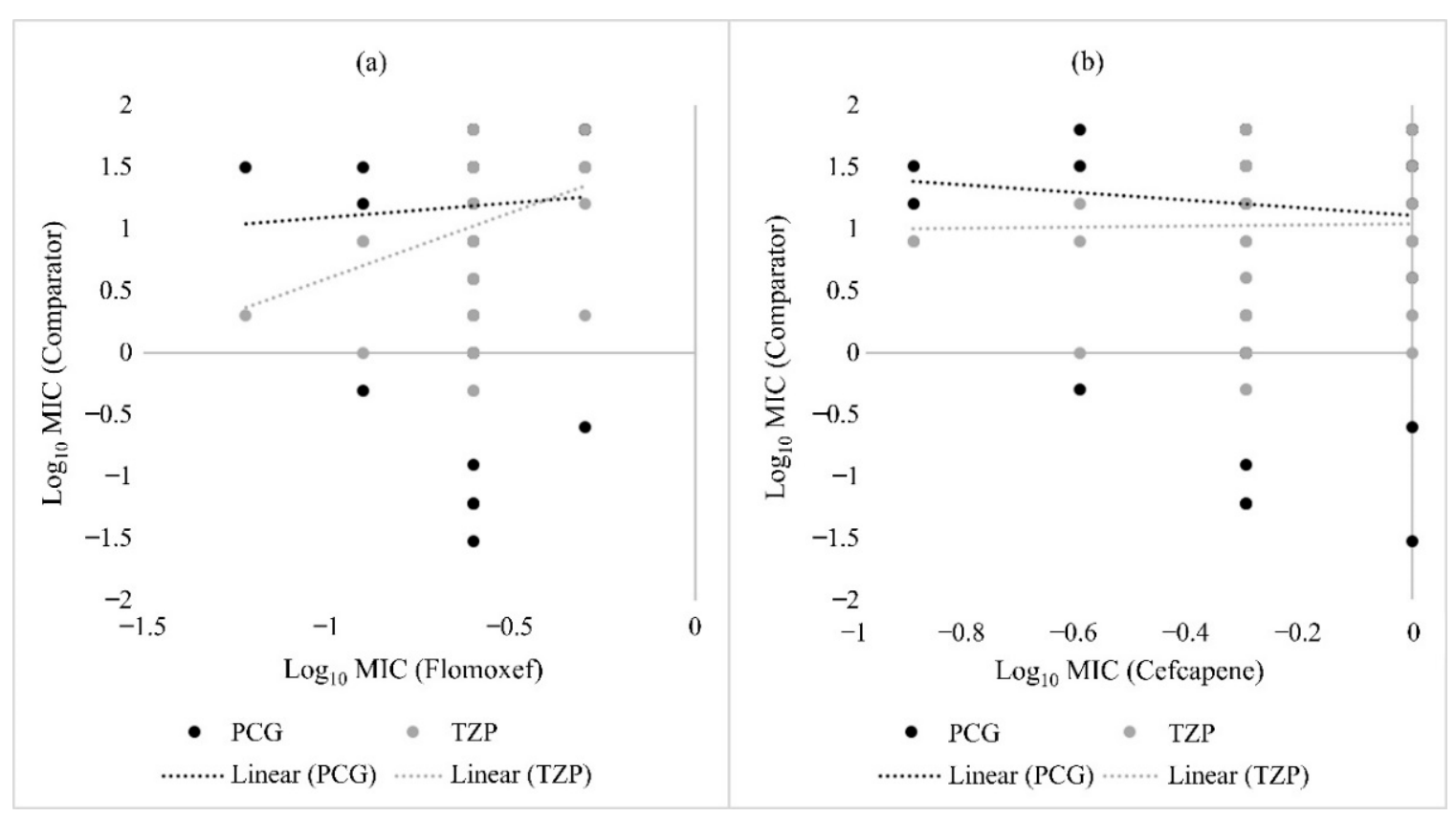

Figure 3. Scatter plots comparing the in vitro activity of penicillin G, piperacillin-tazobactam, flomoxef and cefcapene against MSSA. (a) compares the $\log _{10}$ MIC values of penicillin G (PCG) and piperacillin-tazobactam (TZP) against flomoxef, while (b) compares the $\log _{10}$ MIC values of PCG and TZP against cefcapene. The dotted lines indicate the linear correlation between the comparators. 
(a)

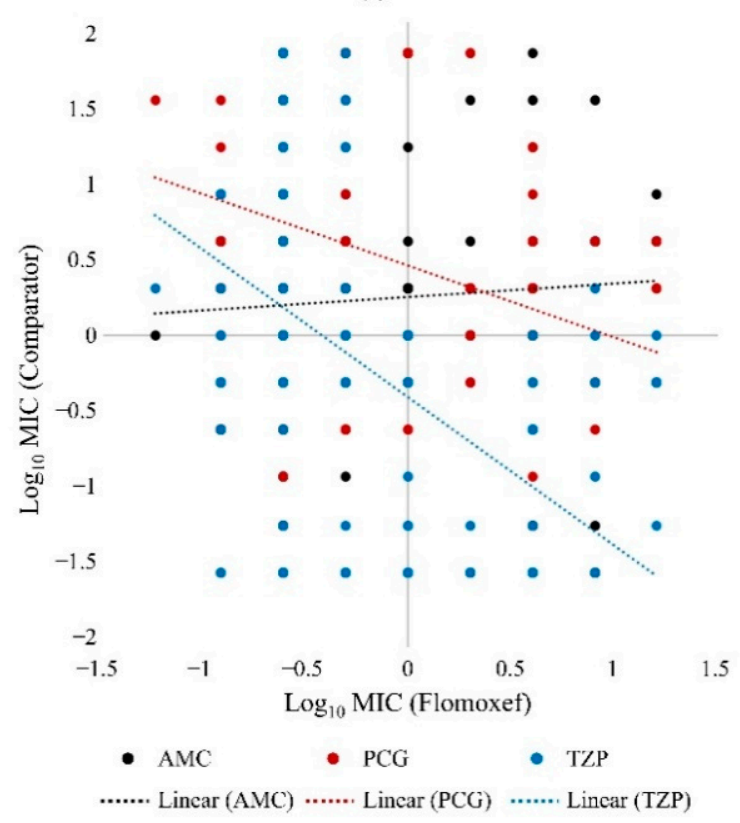

(b)

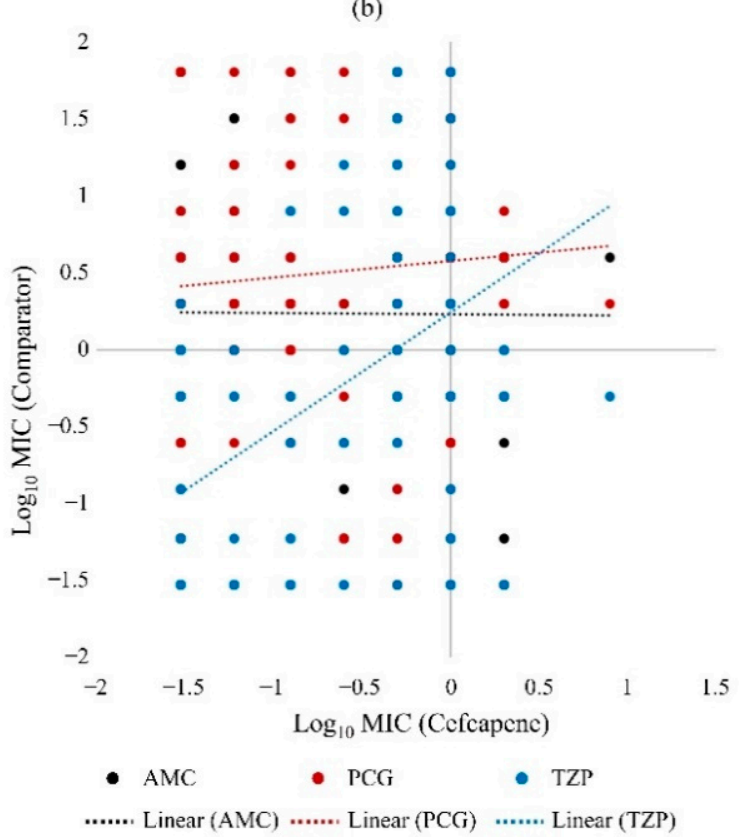

Figure 4. Scatter plots comparing minimum inhibitory concentration (MIC) values of selected $\beta$-lactam antibiotics for 150 bacterial strains. (a) compares the MIC values of amoxicillin-clavulanate (AMC), penicillin G (PCG) and piperacillintazobactam (TZP) against that of flomoxef, while (b) compares the MIC values of AMC, PCG and TZP against that of cefcapene. The dotted lines indicate the linear correlation between the comparators.

A cross-species comparison between flomoxef and cefcapene showed that both antimicrobial agents inhibited the growth of more than half of the organisms at very low concentrations (Table 5). Flomoxef was most active against MSSA (MIC $\leq 1 \mu \mathrm{g} / \mathrm{mL}$ ) while cefcapene was most active against $H$. influenzae (MIC $\leq 1 \mu \mathrm{g} / \mathrm{mL}$ ). By using referral MIC breakpoints, all $\mathrm{H}$. influenzae and MSSA strains were predicted as susceptible to both flomoxef and cefcapene. Most of the S. pneumoniae strains showed susceptible phenotypes for cefcapene $(98 \%)$ and flomoxef $(88 \%)$.

Table 5. Comparison of flomoxef and cefcapene minimum inhibitory concentration values among different bacterial species.

\begin{tabular}{cccccc}
\hline $\begin{array}{c}\text { Antimicrobial } \\
\text { Agent }\end{array}$ & $\begin{array}{c}\text { MIC Range } \\
(\boldsymbol{\mu} \mathbf{g} / \mathbf{m L})\end{array}$ & $\begin{array}{c}\text { Susceptibility } \\
\text { Phenotype }\end{array}$ & $\begin{array}{c}\text { S. pneumoniae } \\
(\boldsymbol{n}) \mathbf{( \% )}\end{array}$ & $\begin{array}{c}\text { H. influenzae } \\
(\boldsymbol{n}) \mathbf{( \% )}\end{array}$ & $\begin{array}{c}\text { MSSA } \\
(\boldsymbol{n}) \mathbf{( \% )}\end{array}$ \\
\hline \multirow{3}{*}{ Flomoxef $^{1}$} & $\leq 1$ & Susceptible & $29(58)$ & $25(50)$ & $50(100)$ \\
& $2-8$ & Susceptible & $15(30)$ & $25(50)$ & $0(0)$ \\
& $\geq 16$ & Resistant & $6(12)$ & $0(0)$ & $0(0)$ \\
\hline \multirow{2}{*}{ Cefcapene $^{2}$} & $\leq 1$ & Susceptible & $40(80)$ & $50(100)$ & $50(100)$ \\
& 2 & Intermediate & $9(18)$ & $0(0)$ & $0(0)$ \\
& $\geq 4$ & Resistant & $1(2)$ & $0(0)$ & $0(0)$ \\
\hline
\end{tabular}

${ }^{1}$ The MIC breakpoints for moxalactam (CLSI) were used as the reference for interpretive criteria of flomoxef.

${ }^{2}$ The MIC breakpoints for ceftriaxone (CLSI) were used as the reference for interpretive criteria of cefcapene.

\section{Discussion}

A total of 150 bacterial strains comprised of three common URTI organisms were examined. All H. influenzae and S. pneumoniae were isolated from paediatric patients, while MSSA was isolated from patients from a wider age range. This sampling outcome was not unexpected as both H. influenzae and S. pneumoniae are the two most common causative agents for RTIs in children. In Malaysia, the Hib conjugate vaccine for $H$. influenzae has been included in the National Immunization Programme. Pneumococcal vaccine was not listed among the mandatory vaccines in our country. Despite the implementation of 
these vaccination programmes, the rates of $S$. pneumoniae and $H$. influenzae remain high among children and cause more severe infections. Due to the high prevalence and reduced susceptibility of S. pneumoniae and H. influenzae strains isolated from children worldwide, therefore we focused on the AMR trends and mechanisms of these two organisms in paediatric patients for this study [15-17]. Contrarily, paediatric RTIs caused by MSSA are less frequent. From the year 2012 to 2015, a total of 7434 S. aureus infections had been reported in UMMC and $76.6 \%$ of the cases were caused by MSSA, among which only $22.2 \%$ involved paediatric patients (unpublished data). This record shows that although MSSA infections occurred more frequently than its methicillin-resistant counterpart, it is somehow less studied. Therefore, there was limited AMR data for MSSA in this region.

The relatively high rates of non-susceptibility to penicillin, amoxicillin-clavulanate and carbapenems in S. pneumoniae are a cause of public health concern among children. Previous studies conducted in the Southeast Asian region have documented relatively high rates of penicillin non-susceptibility ( $>50 \%$ ) among paediatric populations [18-20]. Our findings indicated that $S$. pneumoniae serotype 19F was commonly associated with non-susceptibility to penicillin and carbapenem resistance, in agreement with the previous notion that this serotype often shows greater AMR tendency $[18,19,21]$.

We observed the most frequent mutations at Thr-371-Ala/Ser (STMK motif) and Pro432-Thr (adjacent to SRN motif) in PBP1a, corresponding to the common mutation sites in penicillin non-susceptible $S$. pneumoniae [22,23]. The block mutation identified at amino acid positions 574-577 in PBP1a has been previously associated with intermediate- to high-level penicillin resistance [24,25]. The most frequent mutation in PBP2b occurred at Thr-445-Ala (adjacent to the SSN motif). All strains with Thr-445-Ala substitution showed penicillin $\mathrm{MIC} \geq 0.25 \mu \mathrm{g} / \mathrm{mL}$, consistent with a recent work reporting this mutation to reduce PBP binding affinity by $60 \%$ and resulting in raised penicillin MIC $(>0.25 \mu \mathrm{g} / \mathrm{mL})$ [26]. Additional mutations beyond the active sites of PBP2b observed in this study had been reported to decrease $\beta$-lactams reactivity and is commonly present in strains with penicillin MIC $>0.5 \mu \mathrm{g} / \mathrm{mL}$ [27]. The most common mutations in PBP2x (Thr-338-Ala in STMK motif and Leu-546-Val adjacent to KSG motif) were identified in S. pneumoniae strains exhibiting raised penicillin MICs $(2-8 \mu \mathrm{g} / \mathrm{mL})$, consistent with previous reports associating these mutations with higher-level $\beta$-lactam resistance [28-30]. Similar to other non-susceptible S. pneumoniae reported globally, His-395-Leu adjacent to the SSN motif in PBP2x was not associated with Thr-338-Ala (in STMK motif) and conferred a lower penicillin MIC $(1 \mu \mathrm{g} / \mathrm{mL})$ [28]. The only strain harbouring Met-339-Phe alongside Thr-338-Ala in the STMK motif of PBP2x did not show high penicillin and cefotaxime MIC values (2 and $0.5 \mu \mathrm{g} / \mathrm{mL}$, respectively), although mutation at this site was associated with drastically decreased acylation efficiency of $\beta$-lactams and results in higher penicillin and cefotaxime MICs ( $\geq 4$ and $\geq 2 \mu \mathrm{g} / \mathrm{mL}$, respectively) [30-32]. The combined effect of the mutations at all three PBPs has resulted in the raised penicillin MICs $(\geq 0.25 \mu \mathrm{g} / \mathrm{mL})$ observed in this study, thus accounting for the high $\mathrm{MIC}_{50 / 90}$ values of ticarcillin, ticarcillin-clavulanate and cefoxitin which are known to be less active against penicillin-resistant S. pneumoniae [33,34].

$H$. influenzae remained highly susceptible to most of the $\beta$-lactam antibiotics tested, except ampicillin and cephamycin. The high rate of ampicillin resistance among the URTI strains observed in this study could be the combined effect of $\beta$-lactamase production and penicillin-binding protein 3 (PBP3) alteration. The high prevalence of BLNAR and BLPACR in this study indicates that PBP3 alteration resembles the main resistance mechanism against ampicillin in local $H$. influenzae strains. This is noteworthy since $\beta$-lactamase production has been the main ampicillin resistance mechanism for $H$. influenzae globally except Japan [35]. The majority of the PBP3-altered strains in our study were classified as subgroups II, with mutations that conferred only low-level $\beta$-lactam resistance (lowrPBP3) $[13,36]$. This observation concurred with the previous notion that low-rPBP3 predominates in $H$. influenzae isolated in most parts of the world except Japan and South Korea [37,38]. The high prevalence of PBP3 alteration among our ampicillin-resistant $H$. influenzae strains could have explained the reduced susceptibility to cephamycin since 
PBP3 mutations are also known to confer non-susceptibility to second and third-generation cephalosporins [38].

The high rate of penicillin resistance among the MSSA strains in this study reflects the common AMR trends of $S$. aureus in Malaysia. Indeed, the national surveillance data recorded a consistently high rate of penicillin resistance $(\geq 80 \%)$ among the clinical S. aureus isolated yearly [39]. This is not surprising given the high prevalence of the blaZ gene in local S. aureus populations, including those associated with nasal carriage [40]. The higher MIC values for penicillinase-labile penicillin (ampicillin, piperacillin, and ticarcillin) among the MSSA strains are common in penicillin-resistant but oxacillin-susceptible S. aureus [41]. Ceftazidime (with or without clavulanate) showed high MIC values, which is a predictable observation since ceftazidime is known to be less active against $S$. aureus [42]. The higher activity of penicillinase-stable agents, including the $\beta$-lactam combination agents (except ceftazidime-clavulanate and piperacillin-tazobactam), cephems (except ceftazidime), and carbapenems are expected in MSSA [43]. In contrast with mecA-mediated resistance, blaZmediated penicillin resistance in $S$. aureus rarely produces an effect on other $\beta$-lactam antibiotics even at high inoculum size [44-46].

Flomoxef and cefcapene, currently not available in Malaysia, showed well in vitro activity against the URTI pathogens examined in this study. Both antibiotics were highly effective against $H$. influenzae that were non-susceptible to penicillin and amoxicillinclavulanate. Furthermore, cefcapene showed greater activity against penicillin-resistant MSSA, while flomoxef was highly effective against URTI strains with reduced susceptibility to penicillin and piperacillin-tazobactam. Both cefcapene (third-generation cephalosporin) and flomoxef (previously a fourth-generation cephalosporin but currently grouped in oxacephem (cephalosporin group IIIC)) exhibit broad-spectrum activity against Grampositive and Gram-negative bacteria [47]. However, third-generation cephalosporins are more active against Gram-negative bacteria especially Enterobacteriaceae, Neisseria spp. and $H$. influenzae [48]. Indeed, cefcapene showed lower $\mathrm{MIC}_{50 / 90}$ values in $H$. influenzae compared to S. pneumoniae and MSSA in this study. Although fourth-generation cephalosporins are similar to the third generation, members of this group possess zwitterionic compounds that penetrate through the outer membrane of Gram-negative bacteria more rapidly [49]. Furthermore, fourth-generation cephalosporins show a higher affinity to PBPs compared to $\beta$-lactamase in both Gram-positive and Gram-negative organisms [50]. Our results showed that the PBP alterations that conferred penicillin resistance might not be effective against flomoxef, hence the negative correlation between the susceptibility of these two agents among the URTI organisms.

In short, both cefcapene and flomoxef were highly active against bacterial strains that were increasingly resistant to $\beta$-lactams commonly used to treat URTIs and pneumonia. Based on the Malaysian National Antimicrobial Guideline 2019, penicillin is recommended for the treatment of URTIs, while amoxicillin-clavulanate is recommended for the treatment of both upper and lower RTIs [51]. However, our study shows increased non-susceptibility to penicillin and amoxicillin-clavulanate among the common URTI pathogens. The $\mathrm{MIC}_{50 / 90}$ values of flomoxef reported in this study were comparable with, sometimes slightly lower than, similar studies conducted in China and Japan, indicating its higher activity against local URTI strains [52-54]. Similar to findings reported in Korea, cefcapene showed lower $\mathrm{MIC}_{50 / 90}$ values compared to other cephalosporins [55]. Both cefcapene and flomoxef have been clinically proven to be effective and well-tolerated in patients with RTIs [56-59].

Although our study was a single-site study that involved only small subsets of strains, the data provided herein may improve current knowledge on the extent of non-susceptibility to $\beta$-lactams and the associated resistance mechanisms in local URTI pathogens. Nonetheless, multiple centres and larger sample sizes should be included in future studies to provide a more comprehensive understanding of the $\beta$-lactam resistance trends and mechanisms among the important URTI pathogens in this region. Another limitation of the current study was that only selected genes encoding for penicillin-binding proteins 
( $p b p$ and $f t s \mathrm{I})$ and $\beta$-lactamases $\left(b l a_{\mathrm{TEM}}\right.$ and $\left.b l a_{\mathrm{ROB}}\right)$ were investigated. Although these genes represent the most common $\beta$-lactam resistance mechanisms in S. pneumoniae and $H$. influenzae, other molecular mechanisms could have been accounted for the raised MIC values observed in the strains that lacked these genes (or mutations).

\section{Materials and Methods}

\subsection{Bacterial Strains}

A total of 150 non-duplicated bacterial strains comprised of S. pneumoniae $(n=50)$, $H$. influenzae $(n=50)$, and methicillin-susceptible $S$. aureus (MSSA) $(n=50)$ were revived from the bacterial stock cultures collection in the diagnostic laboratory of University Malaya Medical Centre (UMMC). All strains were isolated from respiratory tract specimens of patients admitted to the UMMC with URTI from 2013 to 2015. Both H. influenzae and S. pneumoniae were collected from only paediatric patients (aged 0-17) while S. aureus was collected from patients of all age groups. All bacterial strains were isolated from bronchoalveolar lavage, nasopharyngeal swab and sputum specimens of the patients. Bacterial strains isolated from other sites were excluded from the study. The isolation and initial identification of the bacterial strains were part of the routine microbiological examination procedures in the hospital's diagnostic laboratory. The identity of the bacterial strains was further confirmed using polymerase chain reaction (PCR) protocols adapted from published studies $[43,60,61]$. S. pneumoniae strains were further subjected to PCR serotyping using previously described protocols [62].

\subsection{Minimum Inhibitory Concentrations and Comparison of In Vitro Activity}

The MICs of twenty $\beta$-lactam antibiotics were determined using the broth microdilution method based on CLSI guidelines [41]. The antimicrobial agents examined in this study include penicillins (ampicillin, penicillin $\mathrm{G}$, piperacillin, and ticarcillin), $\beta$-lactam combination agents (amoxicillin-clavulanate, cefotaxime-clavulanate, ceftazidime-clavulanate, piperacillin-tazobactam, and ticarcillin-clavulanate), cephems (cefmetazole, cefoxitin, cefcapene, cefoperazone, cefotaxime, ceftazidime, ceftriaxone, cefepime, and flomoxef) and carbapenems (imipenem and meropenem). The methicillin susceptibility of the $S$. aureus was further confirmed via determining the MIC of oxacillin in addition to the $\beta$-lactams aforementioned. The MIC values of the antimicrobial agents were interpreted according to the available breakpoints in CLSI guidelines [41]. The median MIC value for each antimicrobial agent is represented as $\mathrm{MIC}_{50}$, and $\mathrm{MIC}_{90}$ indicates a concentration that effectively inhibited $90 \%$ of the tested strains. Scatter plots were generated using $\log _{10} \mathrm{MIC}$ values to compare the activity of flomoxef and cefcapene against the common $\beta$-lactam antibiotics recommended for the treatment of RTIs based on the Malaysian National Antibiotics Guideline [51].

\subsection{Molecular Detection of Penicillin Resistance-Conferring Genes}

S. pneumoniae and H. influenzae strains with non-susceptible phenotypes for ampicillin were examined for potential amino acid substitution in the genes encoding for penicillinbinding proteins (pbp1a, pbp2b, and pbp2x in S. pneumoniae and ftsI, also known as pbp3, in H. influenzae). The primer sequences and PCR conditions for the amplification of $p b p$ and ftsI genes were adapted from published studies [12,22,63]. The PCR products were then purified using MEGAquick-spin ${ }^{\mathrm{TM}}$ Plus Total Fragment DNA Purification Kit (iNtRON Biotechnology, South Korea), and sent for sequencing by a commercial sequencing service provider (First BASE Laboratories, Malaysia). The DNA sequences obtained were then analysed using MEGA-X software [64].

The presence of $\beta$-lactamase genes bla $a_{\mathrm{TEM}}(526 \mathrm{bp}$ ) and bla $\mathrm{ROB}$ (692 bp) in the $H$. influenzae strains were investigated using PCR primers and reaction-mix content adapted from a published study [65]. 


\section{Conclusions}

In conclusion, URTI-associated S. pneumoniae, H. influenzae and MSSA remained largely susceptible to most of the $\beta$-lactams but showed increased non-susceptibility to penicillin antibiotics. High-level ampicillin resistance in $H$. influenzae was mainly mediated by the $b l a_{\text {TEM }}$ gene. Multiple-sites mutation in the PBPs was responsible for the penicillin non-susceptible phenotypes of S. pneumoniae and H. influenzae. Cefcapene and flomoxef showed comparable in vitro activity with cephalosporins and carbapenems, thus could be considered as alternative options for the empirical treatment of URTIs.

Supplementary Materials: The following are available online at https: / www.mdpi.com/article/ 10.3390/pathogens10121602/s1, Table S1: Antimicrobial resistance (AMR) profiles of S. pneumoniae strains $(n=50)$; Table S2: Antimicrobial resistance (AMR) profiles of H. influenzae strains $(n=50)$.

Author Contributions: Conceptualization, C.S.J.T., L.H.T., K.C.L. and S.A.; formal analysis, S.T.N., A.N.M., C.W.C. and L.C.C.; funding acquisition, S.A., L.H.T. and K.C.L.; investigation, S.T.N., A.N.M. and K.A.J.; methodology, C.S.J.T. and S.A.; supervision, C.S.J.T. and S.A.; visualization, S.T.N. and A.N.M.; writing-original draft, S.T.N. and A.N.M.; writing-review and editing, C.S.J.T., S.A., C.W.C., L.C.C., K.A.J., K.C.L. and L.H.T. All authors have read and agreed to the published version of the manuscript.

Funding: This work was partially supported by the Universiti Malaya Research Fund (RU005-2020) and Shionogi Singapore Pte. Ltd.

Institutional Review Board Statement: This study was approved by the Medical Ethics Committee of University Malaya Medical Centre (UMMC) on 6 June 2014 (MEC-ID: 1073.21) and had conformed to the principles embodied in the Declaration of Helsinki.

Informed Consent Statement: This study did not involve human subjects. Only secondary data were collected hence patient's consent was not required.

Data Availability Statement: The datasets used and/or analysed during the current study are available from the corresponding author on reasonable request.

Acknowledgments: This is a collaborative study between the Universiti Malaya (UM) and Shionogi Singapore Pte. Ltd. We thank both UM and Shionogi for providing the materials and facilities for this study.

Conflicts of Interest: The authors declare that they have no conflict of interest.

\section{References}

1. Centre for Clinical Practice at NICE (UK). Respiratory Tract Infections-Antibiotic Prescribing: Prescribing of Antibiotics for SelfLimiting Respiratory Tract Infections in Adults and Children in Primary Care; National Institute for Health and Clinical Excellence: London, UK, 2008.

2. Ministry of Health Malaysia. Ministry of Health Hospitals Admissions Data for Diseases of the Respiratory System. 2018. Available online: http:/ / www.data.gov.my/data/en_US/dataset/kemasukan-ke-hospital-kkm-bagi-diseases-of-the-respiratorysystem-malaysia/resource/0c6d18ca-5a0e-4a3c-9050-5de4d20c5afa (accessed on 24 January 2021).

3. World Health Organization. Prevention of Hospital-Acquired Infections: A Practical Guide, 2nd ed.; Ducel, G., Fabry, J., Nicolle, L., Eds.; World Health Organization: Geneva, Switzerland, 2002.

4. World Health Organization. Pneumonia Fact Sheets: World Health Organization. 2016. Available online: http://www.who.int/ en/news-room/fact-sheets/detail/pneumonia (accessed on 10 February 2021).

5. Hughes, A.J.; Ariffin, N.; Huat, T.L.; Abdul Molok, H.; Hashim, S.; Sarijo, J.; Abd Latif, N.H.; Abu Hanifah, Y.; Kamarulzaman, A. Prevalence of nosocomial infection and antibiotic use at a university medical center in Malaysia. Infect. Control Hosp. Epidemiol 2005, 26, 100-104. [CrossRef]

6. Ministry of Health Malaysia. Ministry of Health Hospitals Mortality Data for Diseases of the Respiratory System. 2018. Available online: http:/ / www.data.gov.my/data/en_US/dataset/kematian-di-hospital-kkm-bagi-diseases-of-the-respiratory-systemmalaysia/resource/3d0f4699-5e75-4d5c-b54c-e88f3420dfe9\# (accessed on 24 January 2021).

7. Kronman, M.P.; Zhou, C.; Mangione-Smith, R. Bacterial prevalence and antimicrobial prescribing trends for acute respiratory tract infections. Pediatrics 2014, 134, e956. [CrossRef]

8. Centers for Disease Control and Prevention, CDC. Appropriate Antibiotic Use: Community Atlanta, Georgia, United States of America Centers for Disease Control and Prevention. 2015. Available online: http://www.cdc.gov/antibiotic-use/community/ for-hcp/index.html (accessed on 7 February 2021). 
9. Teng, C.L.; Tong, S.F.; Khoo, E.M.; Lee, V.; Zailinawati, A.H.; Mimi, O.; Chen, W.S.; Nordin, S. Antibiotics for URTI and UTI-Prescribing in Malaysian primary care settings. Aust. Fam. Physician 2011, 40, 325-329.

10. Huttner, A.; Harbarth, S.; Carlet, J.; Cosgrove, S.; Goossens, H.; Holmes, A.; Jarlier, V.; Voss, A.; Pittet, D. Antimicrobial resistance: A global view from the 2013 World Healthcare-Associated Infections Forum. Antimicrob. Resist. Infect. Control $2013,2,31$. [CrossRef]

11. Ruiz, J. Antimicrobial resistance, from bench-to-publicside. Microbes Infect. Chemother. 2021, 1, e1182. [CrossRef]

12. Dabernat, H.; Delmas, C.; Seguy, M.; Pelissier, R.; Faucon, G.; Bennamani, S.; Pasquier, C. Diversity of beta-lactam resistanceconferring amino acid substitutions in penicillin-binding protein 3 of Haemophilus influenzae. Antimicrob. Agents Chemother. 2002, 46, 2208-2218. [CrossRef]

13. García-Cobos, S.; Campos, J.; Lázaro, E.; Román, F.; Cercenado, E.; García-Rey, C.; Pérez-Vázquez, M.; Oteo, J.; de Abajo, F. Ampicillin-resistant non-beta-lactamase-producing Haemophilus influenzae in Spain: Recent emergence of clonal isolates with increased resistance to cefotaxime and cefixime. Antimicrob. Agents Chemother. 2007, 51, 2564-2573. [CrossRef]

14. Ubukata, K.; Shibasaki, Y.; Yamamoto, K.; Chiba, N.; Hasegawa, K.; Takeuchi, Y.; Sunakawa, K.; Inoue, M.; Konno, M. Association of amino acid substitutions in penicillin-binding protein 3 with beta-lactam resistance in beta-lactamase-negative ampicillinresistant Haemophilus influenzae. Antimicrob. Agents Chemother. 2001, 45, 1693-1699. [CrossRef]

15. Otsuka, T.; Chang, B.; Shirai, T.; Iwaya, A.; Wada, A.; Yamanaka, N.; Okazaki, M. Individual risk factors associated with nasopharyngeal colonization with Streptococcus pneumoniae and Haemophilus influenzae: A Japanese birth cohort study. Pediatr. Infect. Dis. J. 2013, 32, 709-714. [CrossRef]

16. Vasoo, S.; Singh, K.; Hsu, L.Y.; Chiew, Y.F.; Chow, C.; Lin, R.T.; Tambyah, P.A. Increasing antibiotic resistance in Streptococcus pneumoniae colonizing children attending day-care centres in Singapore. Respirology 2011, 16, 1241-1248. [CrossRef]

17. Ito, M.; Hotomi, M.; Maruyama, Y.; Hatano, M.; Sugimoto, H.; Yoshizaki, T.; Yamanaka, N. Clonal spread of beta-lactamaseproducing amoxicillin-clavulanate-resistant (BLPACR) strains of non-typeable Haemophilus influenzae among young children attending a day care in Japan. Int. J. Pediatr. Otorhinolaryngol. 2010, 74, 901-906. [CrossRef]

18. Soh, S.W.; Poh, C.L.; Lin, R.V. Serotype distribution and antimicrobial resistance of Streptococcus pneumoniae isolates from pediatric patients in Singapore. Antimicrob. Agents Chemother. 2000, 44, 2193-2196. [CrossRef]

19. Le, C.-F.; Palanisamy, N.K.; Mohd Yusof, M.Y.; Sekaran, S.D. Capsular Serotype and Antibiotic Resistance of Streptococcus pneumoniae Isolates in Malaysia. PLoS ONE 2011, 6, e19547. [CrossRef]

20. Phongsamart, W.; Srifeungfung, S.; Dejsirilert, S.; Chatsuwan, T.; Nunthapisud, P.; Treerauthaweeraphong, V.; Rungnobhakhun, P.; Chokephaibulkit, K. Serotype distribution and antimicrobial susceptibility of S. pneumoniae causing invasive disease in Thai children younger than 5 years old, 2000-2005. Vaccine 2007, 25, 1275-1280. [CrossRef]

21. Zhang, B.; Gertz, R.E.; Liu, Z.; Li, Z.; Fu, W.; Beall, B. Characterization of highly antimicrobial-resistant clinical pneumococcal isolates recovered in a Chinese hospital during 2009-2010. J. Med. Microbiol. 2012, 61, 42-48. [CrossRef]

22. Goh, S.L.; Kee, B.P.; Abdul Jabar, K.; Chua, K.H.; Nathan, A.M.; Bruyne, J.; Ngoi, S.T.; Teh, C.S.J. Molecular detection and genotypic characterisation of Streptococcus pneumoniae isolated from children in Malaysia. Pathog. Glob. Health 2020, 114, 46-54. [CrossRef]

23. Diawara, I.; Nayme, K.; Katfy, K.; Barguigua, A.; Kettani-Halabi, M.; Belabbes, H.; Timinouni, M.; Zerouali, K.; Elmdaghri, N. Analysis of amino acid motif of penicillin-binding proteins $1 \mathrm{a}, 2 \mathrm{~b}$, and $2 \mathrm{x}$ in invasive Streptococcus pneumoniae nonsusceptible to penicillin isolated from pediatric patients in Casablanca, Morocco. BMC Res. Notes 2018, 11, 632. [CrossRef]

24. Chewapreecha, C.; Marttinen, P.; Croucher, N.J.; Salter, S.J.; Harris, S.R.; Mather, A.E.; Hanage, W.P.; Goldblatt, D.; Nosten, F.H.; Turner, C.; et al. Comprehensive Identification of Single Nucleotide Polymorphisms Associated with Beta-lactam Resistance within Pneumococcal Mosaic Genes. PLoS Genet. 2014, 10, e1004547. [CrossRef]

25. Job, V.; Carapito, R.; Vernet, T.; Dessen, A.; Zapun, A. Common alterations in PBP1a from resistant Streptococcus pneumoniae decrease its reactivity toward beta-lactams: Structural insights. J. Biol. Chem. 2008, 283, 4886-4894. [CrossRef]

26. Varghese, R.; Neeravi, A.; Subramanian, N.; Baskar, P.; Anandhan, K.; Veeraraghavan, B. Analysis of Amino Acid Sequences of Penicillin-Binding Proteins 1a, 2b, and 2x in Invasive Streptococcus pneumoniae Nonsusceptible to Penicillin Isolated from Children in India. Microb. Drug Resist. 2021, 27, 311-319. [CrossRef]

27. Calvez, P.; Breukink, E.; Roper, D.I.; Dib, M.; Contreras-Martel, C.; Zapun, A. Substitutions in PBP2b from $\beta$-Lactam-resistant Streptococcus pneumoniae Have Different Effects on Enzymatic Activity and Drug Reactivity. J. Biol. Chem. 2017, 292, 2854-2865. [CrossRef] [PubMed]

28. Granger, D.; Boily-Larouche, G.; Turgeon, P.; Weiss, K.; Roger, M. Genetic analysis of pbp2x in clinical Streptococcus pneumoniae isolates in Quebec, Canada. J. Antimicrob. Chemother. 2005, 55, 832-839. [CrossRef]

29. Asahi, Y.; Takeuchi, Y.; Ubukata, K. Diversity of substitutions within or adjacent to conserved amino acid motifs of penicillinbinding protein 2X in cephalosporin-resistant Streptococcus pneumoniae isolates. Antimicrob. Agents Chemother. 1999, 43, $1252-1255$. [CrossRef]

30. Nagai, K.; Davies, T.A.; Jacobs, M.R.; Appelbaum, P.C. Effects of amino acid alterations in penicillin-binding proteins (PBPs) $1 \mathrm{a}, 2 \mathrm{~b}$, and $2 \mathrm{x}$ on PBP affinities of penicillin, ampicillin, amoxicillin, cefditoren, cefuroxime, cefprozil, and cefaclor in 18 clinical isolates of penicillin-susceptible, -intermediate, and -resistant pneumococci. Antimicrob. Agents Chemother. 2002, 46, 1273-1280. [CrossRef] 
31. Chesnel, L.; Pernot, L.; Lemaire, D.; Champelovier, D.; Croizé, J.; Dideberg, O.; Vernet, T.; Zapun, A. The structural modifications induced by the M339F substitution in PBP2x from Streptococcus pneumoniae further decreases the susceptibility to beta-lactams of resistant strains. J. Biol. Chem. 2003, 278, 44448-44456. [CrossRef]

32. Sanbongi, Y.; Ida, T.; Ishikawa, M.; Osaki, Y.; Kataoka, H.; Suzuki, T.; Kondo, K.; Ohsawa, F.; Yonezawa, M. Complete sequences of six penicillin-binding protein genes from 40 Streptococcus pneumoniae clinical isolates collected in Japan. Antimicrob. Agents Chemother. 2004, 48, 2244-2250. [CrossRef]

33. Doi, Y.; Chambers, H.F. Penicillins and $\beta$-lactamase inhibitors. In Mandell, Douglas, Bennett's Principles and Practice of Infectious Diseases, 8th ed.; Bennett, J.E., Dolin, R., Blaser, M.J., Eds.; W.B. Saunders: Philadephia, PA, USA, 2015; pp. $263-277$.

34. Strachan, S.A.; Friedland, I.R. Therapy for penicillin-resistant Streptococcus pneumoniae. J. Med. Microbiol. 1995, 43, 237-238. [CrossRef]

35. Jacobs, M.R. Worldwide trends in antimicrobial resistance among common respiratory tract pathogens in children. Pediatr. Infect. Dis. J. 2003, 22, S109-S119. [CrossRef]

36. Yokota, S.-i.; Ohkoshi, Y.; Sato, K.; Fujii, N. High prevalence of $\beta$-lactam-resistant Haemophilus influenzae type b isolates derived from respiratory tract specimens in Japanese patients. Int. J. Infect. Dis. 2009, 13, 584-588. [CrossRef]

37. Ubukata, K.; Chiba, N.; Morozumi, M.; Iwata, S.; Sunakawa, K. Longitudinal surveillance of Haemophilus influenzae isolates from pediatric patients with meningitis throughout Japan, 2000-2011. J. Infect. Chemother. 2013, 19, 34-41. [CrossRef]

38. Skaare, D.; Allum, A.G.; Anthonisen, I.L.; Jenkins, A.; Lia, A.; Strand, L.; Tveten, Y.; Kristiansen, B.E. Mutant ftsI genes in the emergence of penicillin-binding protein-mediated beta-lactam resistance in Haemophilus influenzae in Norway. Clin. Microbiol. Infect. 2010, 16, 1117-1124. [CrossRef]

39. Institute of Medical Research. National Surveillance of Antimicrobial Resistance, Malaysia. 2019. Available online: https: //www.imr.gov.my/MyOHAR/index.php/site/archive_rpt (accessed on 10 February 2021).

40. Zarizal, S.; Yeo, C.C.; Faizal, G.M.; Chew, C.H.; Zakaria, Z.A.; Jamil Al-Obaidi, M.M.; Syafinaz Amin, N.; Mohd Nasir, M.D. Nasal colonisation, antimicrobial susceptibility and genotypic pattern of Staphylococcus aureus among agricultural biotechnology students in Besut, Terengganu, east coast of Malaysia. Trop. Med. Int. Health 2018, 23, 905-913. [CrossRef]

41. CLSI. Performance standards for antimicrobial susceptibility testing: Twenty-fifth informational supplement. In CLSI Document M100-S25; CLSI: Wayne, PA, USA, 2015.

42. Richards, D.M.; Brogden, R.N. Ceftazidime. Drugs 1985, 29, 105-161. [CrossRef]

43. Brakstad, O.G.; Aasbakk, K.; Maeland, J.A. Detection of Staphylococcus aureus by polymerase chain reaction amplification of the nuc gene. J. Clin. Microbiol. 1992, 30, 1654-1660. [CrossRef]

44. Song, K.H.; Jung, S.I.; Lee, S.; Park, S.; Kim, E.S.; Park, K.H.; Park, W.B.; Choe, P.G.; Kim, Y.K.; Kwak, Y.G.; et al. Inoculum effect of methicillin-susceptible Staphylococcus aureus against broad-spectrum beta-lactam antibiotics. Eur. J. Clin. Microbiol. Infect. Dis. 2019, 38, 67-74. [CrossRef]

45. Saeki, M.; Shinagawa, M.; Yakuwa, Y.; Nirasawa, S.; Sato, Y.; Yanagihara, N.; Takahashi, S. Inoculum effect of high concentrations of methicillin-susceptible Staphylococcus aureus on the efficacy of cefazolin and other beta-lactams. J. Infect. Chemother. 2018, 24, 212-215. [CrossRef]

46. Stapleton, P.D.; Taylor, P.W. Methicillin resistance in Staphylococcus aureus: Mechanisms and modulation. Sci. Prog. 2002, 85, 57-72. [CrossRef]

47. Bryskier, A.; Aszodi, J.; Chantot, J.-F. Parenteral cephalosporin classification. Expert Opin. Investig. Drugs 1994, 3, 145-171. [CrossRef]

48. Arumugham, V.B.; Gujarathi, R.; Cascella, M. Third Generation Cephalosporins. In StatPearls; StatPearls Publishing LLC.: Treasure Island, FL, USA, 2021.

49. Hancock, R.E.; Bellido, F. Antibacterial in vitro activity of fourth generation cephalosporins. J. Chemother. 1996, 8 (Suppl. S2), 31-36.

50. Pucci, M.J.; Boice-Sowek, J.; Kessler, R.E.; Dougherty, T.J. Comparison of cefepime, cefpirome, and cefaclidine binding affinities for penicillin-binding proteins in Escherichia coli K-12 and Pseudomonas aeruginosa SC8329. Antimicrob. Agents Chemother. 1991, 35, 2312-2317. [CrossRef]

51. Ministry of Health Malaysia. National Antimicrobial Guideline 2019. In Programme PS.; Malaysia Pharmaceutical Services Programme, Petaling, J., Eds.; Ministry of Health Malaysia \& Pharmaceutical Services Programme: Selangor, Malaysia, 2019.

52. Cui, L.; Li, Y.; Lv, Y.; Xue, F.; Liu, J. Antimicrobial resistance surveillance of flomoxef in China. J. Infect. Chemother. 2015, 21, 402-404. [CrossRef]

53. Yang, Q.; Zhang, H.; Cheng, J.; Xu, Z.; Hou, X.; Xu, Y. Flomoxef showed excellent in vitro activity against clinically important gram-positive and gram-negative pathogens causing community- and hospital-associated infections. Diagn. Microbiol. Infect. Dis. 2015, 81, 269-274. [CrossRef]

54. Takakura, M.; Fukuda, Y.; Nomura, N.; Mitsuyama, J.; Yamaoka, K.; Asano, Y.; Sawamura, H.; Katsuragawa, K.; Hashido, H.; Matsukawa, Y.; et al. Antibacterial susceptibility surveillance of Haemophilus influenzae isolated from pediatric patients in Gifu and Aichi prefectures (2009-2010). Jpn. J. Antibiot. 2012, 65, 305-321. [PubMed]

55. Choo, E.J.; Kwak, Y.G.; Lee, M.S.; Jeong, J.Y.; Choi, S.H.; Kim, N.J.; Kim, Y.S.; Woo, J.H.; Ryu, J. In vitro Antimicrobial Activity of Cefcapene against Clinical Isolates. Infect. Chemother. 2005, 37, 133-137. 
56. Kanegae, H.; Yamada, H.; Yamaguchi, T.; Kuroki, S.; Katoh, O. Clinical studies on flomoxef in respiratory tract infections. Jpn. J. Antibiot. 1987, 40, 1803-1808. [PubMed]

57. Sato, H.; Narita, A.; Nakazawa, S.; Suzuki, H.; Mastumoto, K.; Nakanishi, Y.; Nakazawa, S.; Niino, K.; Nakada, Y. The study of flomoxef in the pediatric field. Jpn. J. Antibiot. 1987, 40, 1349-1363. [PubMed]

58. Saito, A.; Hiraga, Y.; Watanabe, A.; Saito, A.; Shimada, K.; Kobayashi, H.; Odagiri, S.; Miki, F.; Soejima, R.; Oizumi, K.; et al Comparative clinical study of cefcapene pivoxil and cefteram pivoxil in chronic respiratory tract infections by a double-blind method. J. Int. Med. Res. 2004, 32, 590-607. [CrossRef]

59. Wang, H.L.; Huo, L.; Wang, Z.S.; Zhao, J.Y.; Xue, X.; Ge, G.Z.; Ren, J.L.; Xia, T.; Han, X.W.; Yue, H.M.; et al. Multicenter, double-blind, randomized controlled clinical trial of cefcapene pivoxil hydrochloride tablets in the treatment of acute bacterial infections. Chin. J. Clin. Pharmacol. 2012, 1, R978.11.

60. Enright, M.C.; Spratt, B.G. A multilocus sequence typing scheme for Streptococcus pneumoniae: Identification of clones associated with serious invasive disease. Microbiology 1998, 144 (Pt 11), 3049-3060. [CrossRef]

61. Torigoe, H.; Seki, M.; Yamashita, Y.; Sugaya, A.; Maeno, M. Detection of Haemophilus influenzae by loop-mediated isothermal amplification (LAMP) of the outer membrane protein P6 gene. Jpn. J. Infect. Dis. 2007, 60, 55-58. [PubMed]

62. Dias, C.A.; Teixeira, L.M.; Carvalho, M.D.G.; Beall, B. Sequential multiplex PCR for determining capsular serotypes of pneumococci recovered from Brazilian children. J. Med. Microbiol. 2007, 56, 1185-1188. [CrossRef] [PubMed]

63. Zhou, X.; Liu, J.; Zhang, Z.; Liu, Y.; Wang, Y.; Liu, Y. Molecular characteristics of penicillin-binding protein 2b, 2x and 1a sequences in Streptococcus pneumoniae isolates causing invasive diseases among children in Northeast China. Eur. J. Clin. Microbiol. Infect. Dis. 2016, 35, 633-645. [CrossRef] [PubMed]

64. Kumar, S.; Stecher, G.; Li, M.; Knyaz, C.; Tamura, K. MEGA X: Molecular Evolutionary Genetics Analysis across Computing Platforms. Mol. Biol. Evol. 2018, 35, 1547-1549. [CrossRef] [PubMed]

65. Tenover, F.C.; Huang, M.B.; Rasheed, J.K.; Persing, D.H. Development of PCR assays to detect ampicillin resistance genes in cerebrospinal fluid samples containing Haemophilus influenzae. J. Clin. Microbiol. 1994, 32, 2729-2737. [CrossRef] [PubMed] 